\title{
Teaching Me Softly: Experiences and Reflections on Informal Educational Game Design
}

\author{
Ulrich Wechselberger \\ University of Koblenz-Landau, \\ Institute For Computational Visualistics, \\ Universitaetsstr. 1, 56070 Koblenz, Germany \\ wberger@uni-koblenz.de
}

\begin{abstract}
Video games are highly engaging environments. Therefore, there is a growing interest in harnessing their motivational potential via game-based learning. However, putting curricular content into digital games is not trivial. Many educational games fail to combine teaching and gameplay in a subtle way, thereby suffer from low-grade design and fail to utilise the motivational potential of video games.

This article explicates some main issues of educational games and reflects on an approach to a more informal and harmonic design for educational games. Furthermore, it describes the "Eduventure II", a research project investigating and testing these methods. The game developed in this prototype links the curriculum to narrative, simulation and game play layers. The here presented text describes the theoretical background, issues, concept and implementation of the prototype, as well as the lessons learnt from a pedagogical perspective.
\end{abstract}

Keywords: Game-Based Learning, Educational Game Design.

\section{Introduction}

Game-based learning has become an important issue for economy, society and research. The demand of lifelong learning increases the need for effective, motivating learning tools. Meanwhile, computer graphics and game technology made a quantum leap. Moreover, computer games have become common and popular among young people. As a result, scientists, educators and pedagogues consider computer games as an educational tool. However, this subject still has issues. This article addresses one of them - inferior integration of the learning content into the game - and reflects some theoretical thoughts and practical experiences regarding a more elegant and "subtle" educational game design.

At first, this article distinguishes play, games and computer games, as well as several uses of game-based learning. Part two discusses the potential of game-based learning from a pedagogical perspective, stressing on motivational and didactical benefits of digital games. The following sections describe a way to combine educational content with video games and its practical application within the Eduventure 
II, a learning adventure targeting historical knowledge. Last, but not least, some conclusions regarding the used approach and further research are drawn.

\section{From Play to Game-Based Learning}

This article will be prefaced with a short paragraph on terminology. Play takes place within a frame often regarded as the "magic circle" [1, p. 94]. Within this frame, the player does not encounter negative consequences or functional pressures, which thereby supports "lusory behaviour" 2. The world within the magic circle is not only risk-free, but also imaginary. Players overcome the borders of reality and apply new meanings to objects: During play, a matchbox can become a train, a car, a house or whatever the player wants it to be. Fabricatore refers to this circumstance as the concept of "as if" 2.

Salen and Zimmerman define a game as "a system in which players engage in an artificial conflict, defined by rules, that results in a quantifiable outcome" [1, p. 80]. By mentioning the artificial character of game worlds, this definition adapts the concept of "as if". To simplify matters, this paper uses the terms digital game, video game and computer game synonymously, following Juul's definition: A video or computer game is, "generally speaking, a game played using computer power and a video display" [3, p. 36].

The terminology on game-based learning, however, still seems to be somewhat fuzzy and vague. Nevertheless, one could distinguish two forms of learning games. Serious games focus on the technical potential of video games for training and simulation, stressing authenticity and realism of the educational content. In contrast, educational games try to preserve a balance of fun and education, imparting the educational content in an entertaining and playful manner [4. Both serious games and educational games (and even regular video games when applied in an educational context) can be used for several purposes, which I suggest to break down into four different ideal types. First, learning games can take over the role of a teacher, imparting knowledge and information. Secondly, they can be designed in order to train specific capabilities and skills. They can also be used for overlearning and recapitulating (as in the "Triple A Game Show" [5]). Last, but not least, pedagogues can use them as some sort of "bait", which makes it much easier for them to get in touch with their clients and build a relationship. However, this article does not cover all possible forms and purposes of learning games. It focuses (a) on educational games that are (b) used for teaching.

\section{Pedagogical Potential of Game-Based Learning}

Computer games can be powerful educational tools mainly for two reasons: First, they incorporate well-established learning principles and provide resources for authentic simulation. Secondly, computer games are fun to play and therefore engaging. However, this does not automatically mean that educational games benefit from these factors as well. The following section provides background information and research findings concerning these issues. 


\subsection{Computer Games and Learning}

Playing is often connected to learning processes. Fabricatore for instance connects the process of playing video games with several learning occasions (cf. figure 1), such as training of analytic, strategic and psychomotor skills as well as acquisition of game-relevant knowledge [2]. Moreover, scientists have indicated several learning principles embodied in computer games. For instance, Gentile and Gentile found seven factors beneficial for learning, including adaptation to player skills, interactivity, practice and overlearning [6]. Van Eck states that learning in computer games "takes place within a meaningful (to the game) context" [7, p. 18] and emphasises the role of a relevant context for learning principles (such as situated cognition and viability). Gee even elaborated 36 educational values of computer games, including motivation to start and keep on learning, customisation, possibility to test hypotheses and others [8]. Also, due to the increasing performance of state of the art hardware, video games can simulate graphics, physics and even artificial intelligence (e.g. in the game " $f a$ cade" 9]). This enables the player to interact with systems that (for different reasons) can not be examined in real life (e.g. historical societies, hazardous environments, biological microsystems). Thereupon, one could consider computer games as effective learning environments.

On the other hand, research findings about learning in video games are unsatisfying. On the one hand, there is evidence of computer games very effectively supporting a narrow scope of psychomotor skills. They also train cognitive capabilities such as visual attention skills, spatial visualisation, problem solving,

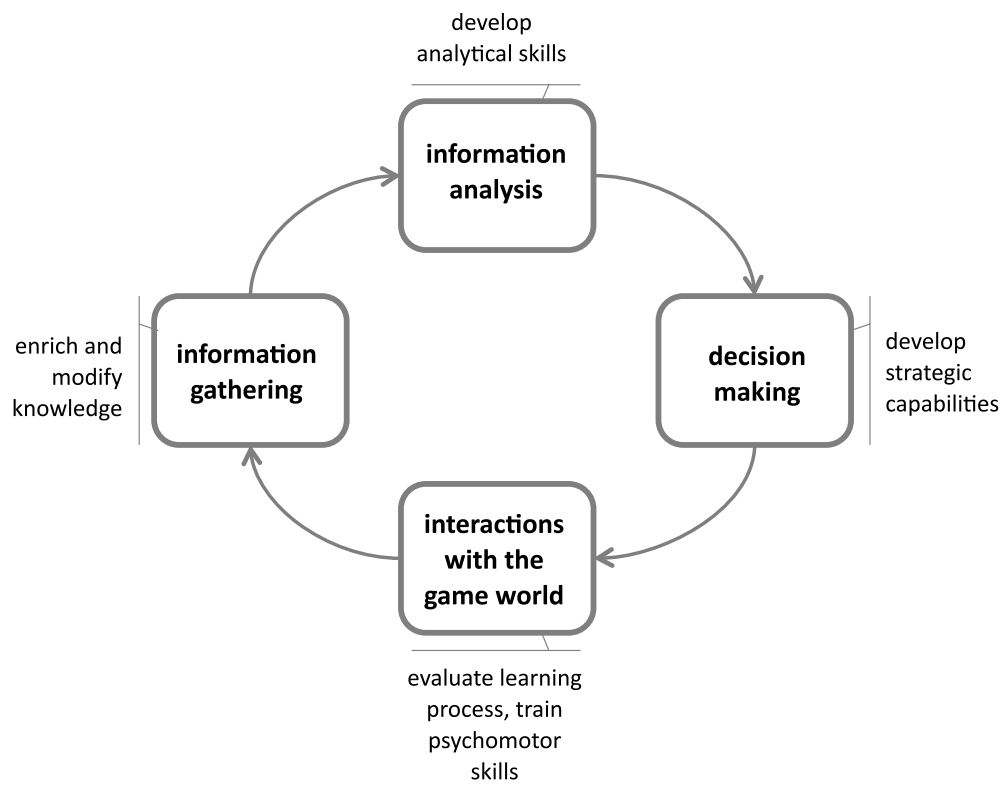

Fig. 1. Learning occasions within computer game play regarding to Fabricatore [2] 
creative and critical thought [10. However, research findings about knowledge acquisition through video games are rare and contradictous. This also applies to the internalisation of norms and moral values. Both values and information seem to be bound within the magic circle, which may in many cases block learning transfer into real life. This may be due to certain theoretical problems which arise when dealing with complex issues such as knowledge construction. Section 4.2 will deal with this issue in detail.

\subsection{Motivational Effects of Computer Games}

Playing games is fun. Play and games have been used to enhance the interest of adolescents in useful, yet somewhat unexciting matters (for example curricular contents) for decades. Thus, the most important hidden agenda regarding game-based learning is to utilise the motivational power of play and games for educational purposes. But where does this motivational potential come from? Many scientists believe that the power a player can wield over his environment while still challenged is a very important source of intrinsic motivation [11. Computer games provide instant feedback and thereby deliver instant gratification. They also come up with other motivating features such as aesthetic graphical representation, a wide variation of options and scenarios, and others 12, pp. 128-129]. Accordingly, computer games appear to have great motivational potential.

However, although video games are very entertaining, learning games are not necessarily fun as well. Two main problems may come up when trying to benefit from the motivational potential by using learning games in an educational context: As mentioned earlier in this article, play is free of functional pressures and does not have negative consequences. Thus, a teacher cannot impose playing a game on a pupil without running the risk of disrupting the nature of play (and thereby corrupting part of its motivational source). Video games may become "teacherised" in an educational context 4, leading to the loss of their engaging potential. This is a constitutive problem with play and games used for teaching: By being exploited for purposes outside of the magic circle, play and games become serious, which is somehow paradox. This constitutive issue may not be fixable by game design. It is, however, more of a hypothetical nature. The second problem is more of a practical nature and concerns game design. Curricular objectives and game goals are often incongruent [1113], and, as a result, educational games are often of inferior quality. Seymour Papert criticised the low-grade design of most edutainment products and educational games: "Shavian reversals - offspring that keep the bad features of each parent and lose the good ones - are visible in most software products that claim to come from a mating of education and entertainment" [14, p. 88]. Indeed, in most educational games there seems to be little cohesion between educational content and game structure 2. Integration of the curricular content is stilted and artificial, thus gameplay, fun and entertainment are corrupted.

The here presented article concentrates on the second issue. 


\section{Theoretical Reflections on Video Game Semiotics}

In order to overcome the obstacle of inferior educational game design, one has to find subtle, elegant ways to connect video game structure and educational content. Fabricatore proposed that educational game designers should embed knowledge "naturally" and with contextual relevance into gameplay [2, and curricular tasks should become elements of the gameplay. He exemplifies his thoughts by describing a Super Mario game. In this game, collectable coins are replaced by educational content (e.g. numbers). This approach can be taken even one step further. First, the connection between learning tasks and gameplay could be strengthened by creating a functional, semantic relation between them (this thought will be elaborated in the "game player" section later in this article (cf. section 4.1)). Secondly, it might not be possible to connect any kind of information to gameplay. For these contents one has to identify and elaborate further "information carriers" within digital games. In order to achieve this, one has to understand the semiotic structure of video games.

\subsection{Semiotic Structure of Video Games}

A useful semiotic framework, suitable both for game analysis and design, was introduced by Lindley [15. He refers to video games as ludic systems involving three layers of encoding, each having different tradition, language and methodology: game play, narrative and simulation. Various game genres may focus on different layers (cf. figure 21).

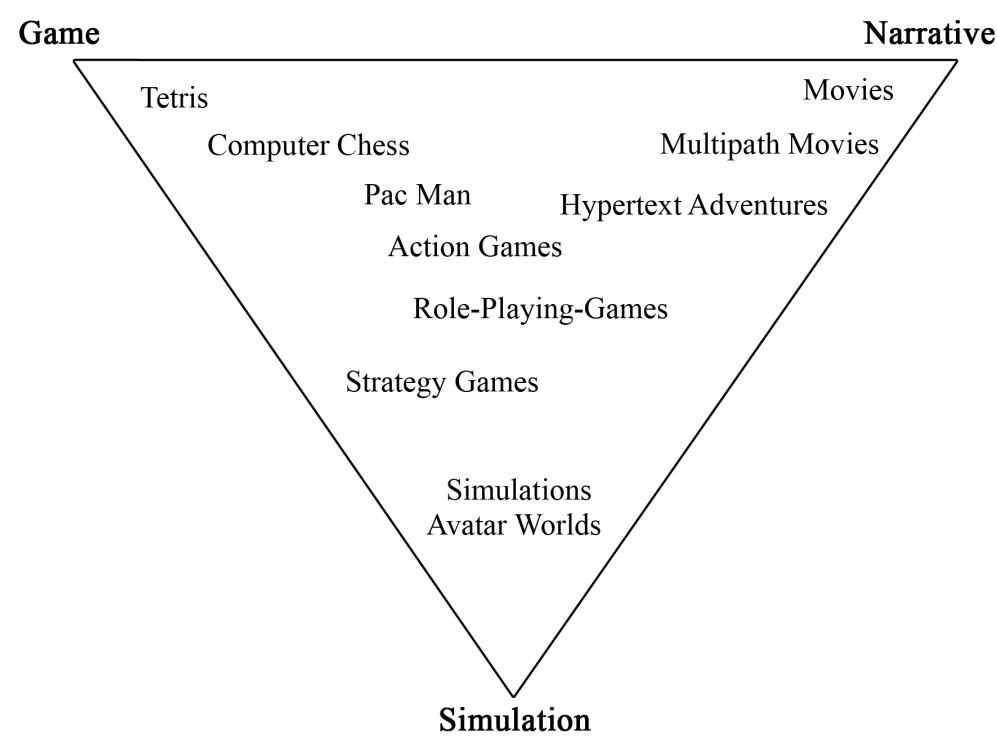

Fig. 2. Semiotic layers within computer games regarding to Lindley [15] 
Game Layer. The most obvious semiotic level of video games is the game layer. Many abstract games like Pong [16 take place primarily on this layer. Lindley describes it as a "framework of agreed rules" 15. These rules define the possibilities and boundaries of what a player can legally do while playing a game. They also specify the consequences of player actions. According to the more practical definition by Adams and Rollings [17, pp. 12-14], gameplay is constituted by the challenges a player faces during the game as well as the actions he addresses them with. Adams and Rollings describe numerous common challenges, for example:

- logical and mathematical challenges,

- factual knowledge challenges,

- exploration challenges (such as spatial awareness, mazes, etc.),

- conflict (stressing strategy, stealth etc.),

- economic challenges (e.g. achieving balance between several elements in a system),

- and others (for a complete list cf. [17, pp. 289-302].

In the course of subtle educational game design, these challenges could be semantically connected to the cognitive tasks postulated by the curriculum. Imagine a game that is supposed to teach the volumetric mass density of certain materials. A common, yet stilted and artificial approach would be to create, for example, an adventure game that just lets you collect materials, providing information regarding their mass density separately. In contrast, an elegant educational game design would, for instance, connect the mass density of the materials to an economic challenge and design a system (e.g. a large construction of teeter-tooters) where the player has to position the materials while maintaining the physical balance of the whole structure. This way, the educational content would be semantically connected to the gameplay. The computer would simulate the physics in realtime and thereby provide instant feedback regarding the effect on the balance. Also, this way the learning content would prove useful for achieving the goal of the game, thereby creating viability (cf. section 3.1). This game might be both more fun to play and more didactically effective, for the educational content is not only connected to gameplay, but also to the learning principles used in computer games.

Narrative Layer. The second game layer described by Lindley is the narrative layer. Games like hypertext adventures and game books take place mainly on this layer. Lindley defines narrative as "a representation of the causally interconnected events of a story" 15. According to Lindley, a common narrative structure of computer games consists of three acts: establishment of the conflict, playing out its implication and finally solving it. In a much more detailed attempt, Glassner [18, pp. 35-123] breaks down narrative structures into three different parts:

- characters (consisting of several nested masks),

- plot (following common structures and containing typical elements)

- and story technique (providing a wide variety of narrative devices). 
These parts may provide many "information carriers" for curricular content. For instance, designers of an educational game could bring back historical celebrities to a new virtual life in the form of non-player-characters. Information on the background of these celebrities could be connected to character masks and behaviour. Common plot structures and story techniques may be used to add connotations which may also encode curricular information (just imagine the semantic difference it makes if you connect a renowned, historical president not to the role of a hero, but to the role of a villain instead).

Simulation Level. Simulation games like Civilization [19] focus on the simulation level. According to Lindley, the simulation level addresses basic features and functions of the game world: It is "the level at which the authored logic and parameters of a game system together with the specific interactive choices of the player determine an (implied) diegetic (i.e. represented) world" [15. Logic and parameters include, but are not limited to animation, physics, non-player character behaviour (and others). Moreover, this layer of semiotic encoding is based on an underlying set of rules, functions and constraints, developed by the game designers. Modern computers and game engines are capable of simulating these sets quite realistically and convincing. Interdependencies within complex systems (for instance ecosystems) can be rendered in realtime, thus creating authentic interactive simulation environments. In addition, modern computer technology simulate physics and photorealistic graphics. For educational games, these simulations may be directly connected to curricular content.

Conclusion. Lindley's framework provides three useful semiotic levels and thereby reveals adequate information carriers. Embedding knowledge deeply into these semiotic layers could lead to a harmonic and subtle educational game design, preserving game structure and thereby fun and entertainment. However, there may be a downside of a suchlike approach, which I would like to touch in the following section.

\subsection{A Potential Downside of Subtle Educational Game Design}

Hypothetically, the didactical potential of the above-mentioned approach may be reduced by mental structures referred to as frames or schemata [20. These cognitive structures organise the perception of all kinds of data (e.g. signs, objects, situations) by applying meaning to them. During this process, an individual generates information and finally constructs and modifies its knowledge. This process is highly dependent on the situational context where the information is gathered. Cues help to identify the context and to select a respective cognitive frame for interpretation and evaluation of the information within. In brief, cues have an effect on the framing processes, thereby affecting perception and knowledge acquisition. A work by Robinson et. al. 21] demonstrates the impact of cues-affected, cognitive frames on perception: During an experiment, children had to rate foods that were served in both branded and unbranded wrappings. 
Although all bags contained identical foods, the test subjects stated that the ones in the branded wrapper tasted better than the others. Robinson and his colleagues traced this result back to the impact of branding on the children's perception. This research may be connected to cognitive frames ("branded foods are generally better than unbranded foods") which are activated by cues and context (branded wrappers) and produce (subjective) meaning and information ("I like this food better than that one").

The concept of schemata and frames can also be applied to the reception of educational games. Imagine adolescents, playing a leisure game (or an educational game, subtly combining curricular content and gameplay) they believe to have no didactical purposes. Regarding the definition of play and games, the players stay within the magic circle, an artificial world mentally separated from the real word, following the concept of "as if" (cf. section 2). In principle, this magic circle is nothing but cognitive frame, separating meanings of the game world from the ones in the real world and organising the players' perceptions. Thus, if there is no "wrapping" branding the game elements as educational content, the players may only activate their "play and games" schemata. Because without any curricular cues, how should they know that they are dealing with authentic pieces of information that are supposed to be used in the real world? As a result, when it comes to knowledge acquisition through game-based learning, educational content may theoretically be overlooked. This hypothesis might apply mostly to (a) games that teach information (whose content is especially context-specific) and (b) educational games and regular video games (because, contrary to serious games, they usually miss the "this is educational content" cues). This hypothesis might explain the research findings mentioned above, which primarily document the training of skills and capabilities rather than the teaching knowledge in computer games.

Both this issue and the approach of an informal educational game design as described earlier have been researched within a project that was carried out by the Institute For Computational Visualistics at the University of KoblenzLandau in Germany. This project will be introduced in the following section.

\section{The Eduventure-II-Project}

\subsection{Research Questions and Project Procedure}

The Eduventure-II-project attends to the following questions:

1. How can curricular content be embedded into an educational game without spoiling the structure of the game and the coherence of the subject matter?

2. Can a game following such a design approach engange players more effectively? How do the players perceive the educational content within the game?

3. What practical experience can be gathered that could be useful for similar projects?

In order to address these issues, an educational game prototype was designed within the project, which was supposed to serve as a test subject. At first, the 
curricular content was defined. In the meantime, video game semiotics as well as the combination of learning content and game structure was investigated. Based on these two steps an educational game was designed. After that, the game prototype was implemented, which was meant to be followed by the evaluation of the design approach and prototype. However, due to a cut of funding, the project was discontinued during the implementation phase. Nevertheless, our project team was able to design a game concept and implement a working, yet reduced prototype. The next section deals with the details of the concept.

\subsection{Educational Content}

For many pupils, history is a dry subject, and they are not particularly engaged by history lessons. The potential motivational and didactical benefits of video games may be of great value when addressing this issue. For this reason, the project focused on German cultural heritage and history. The curriculum consisted primarily of the following learning contents:

- After years of democracy under occupying forces from France, the city of Koblenz got under Prussian rule due to the Congress of Vienna in 1814/1815 and was subjected to the nationalistic authority of Prussia.

- After obtaining the city of Koblenz, the Prussian occupiers built a huge fortification system, designed in conformance with the most recent findings in fortification technology, protecting the city.

- This fortification system was said to be impregnable by force. It could only be compromised by either treason or espionage.

- There were plenty of disagreements between the citizens of Koblenz and the Prussian forces, based on ideological and organisational issues.

- Life was hard for the Prussian soldiers, for the fortress was not very comfortable and daily routines were exhausting.

- In 1848, the civilian population in the German states rebelled against the authorities, demanding freedom, democracy and national unity.

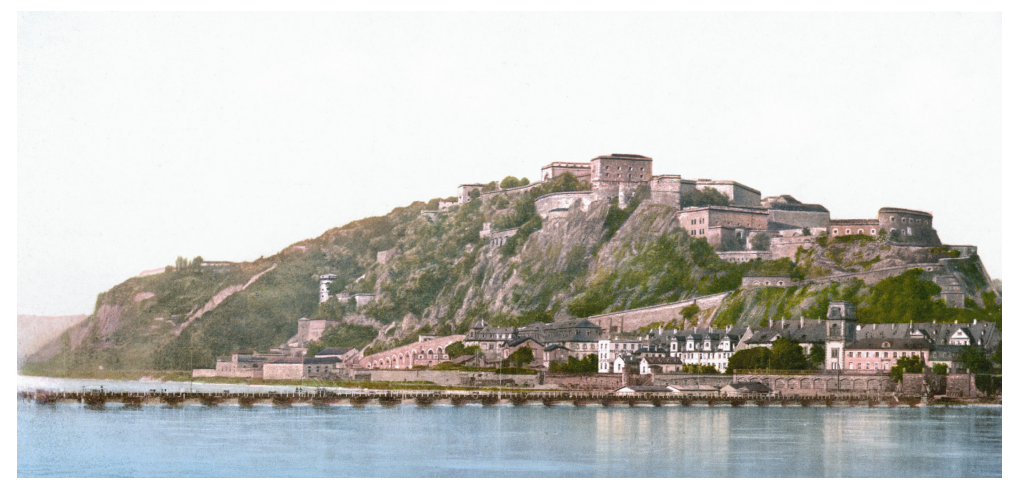

Fig. 3. A photograph of the Prussian fortress from the year 1900 
- As a result, the military forces armed the fortresses in Koblenz in order to awe the citizens of Koblenz, keeping them from joining the rebellion. This arming consisted of several strategic measures.

The next section describes how this educational content was connected to the semiotic layers of the game.

\subsection{Game Description}

Game Concept. The Eduventure-II-prototype is a classic role playing / adventure game. We chose this game type because its structure is evenly distributed among the three semiotic layers mentioned above (cf. figure 2).

Within the game, the player assumes the role of a thief. He is hired by an éminence grise to infiltrate the Prussian fortress during the Revolutions of 1848 in the German states. His objectives are to gather as much information about the Prussian forces as possible, to capture the contents of a mysterious box brought to the headquarters of the fortress and to find vulnerabilities in the Prussian system of defence. To accomplish this, the player character joins a group of workers that are arming the fortress. Next, he waits for the night in a hiding place. After sunset, he sneaks into the fortress, searching for an adequate uniform he could wear during the day. Having found a uniform, he is able to enter the core of the fortress and finally fulfil his remaining objective.

This gameplay experience was connected to the educational content that was described above. On the simulation layer, we encoded information about uniforms, equipment, architectural structures and tasks regarding the arming. For example, virtual uniforms and models are authentic. Also, we paid much attention to a high recognition value of the architecture. Additionally, we resorted to the game engines capability of importing heightmaps for terrain rendering. This way we were able to use real geoinformation (acquired by the local land surveying office) for the simulation of the fortresses environment (cf. figure 4).

Furthermore, we encoded information on the narrative level. Story and virtual characters were connected to information about the background of the revolutions, the conflict between civilians and Prussian forces, and what life was like for a soldier working at the fortress. For instance, dialogues with labourers and soldiers reveal details about the differences between the civilians and military forces. Also, some archetypical virtual characters demonstrate the rough mentality of the Prussian occupying forces. In addition, the recruitment of the player character as a secret agent (and therefore the initial point of the story) is linked directly to the political background in 1848. In order to accentuate the tremendous obstacle the fortresses walls posed for potential attackers (cf. figure [5), we connected the task of conquering it to the common plot element "crossing the threshold" (cf. [18, pp. 61-62].

Last but not least, we connected some educational elements to the gameplay layer. Knowledge encoded on this layer includes Prussian fortification strategy, the tasks arming consisted of, as well as Prussian uniforms and equipment. For example, the player has to disguise himself as a Prussian soldier. Addressing factual knowledge challenge (cf. section 4.1), this task would result in getting caught 


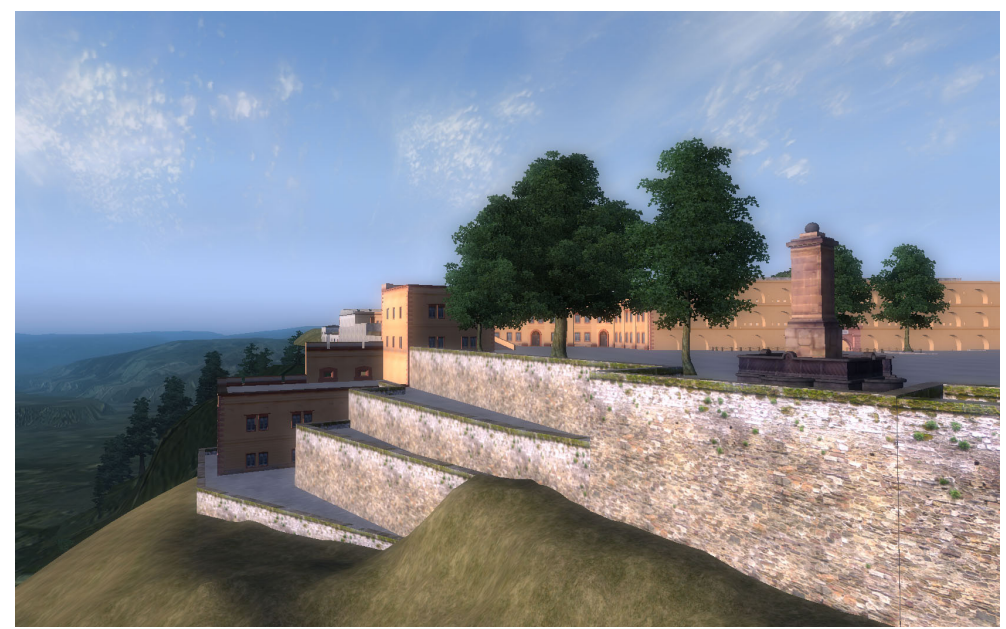

Fig. 4. The Eduventure's terrain rendering is based on real geoinformation

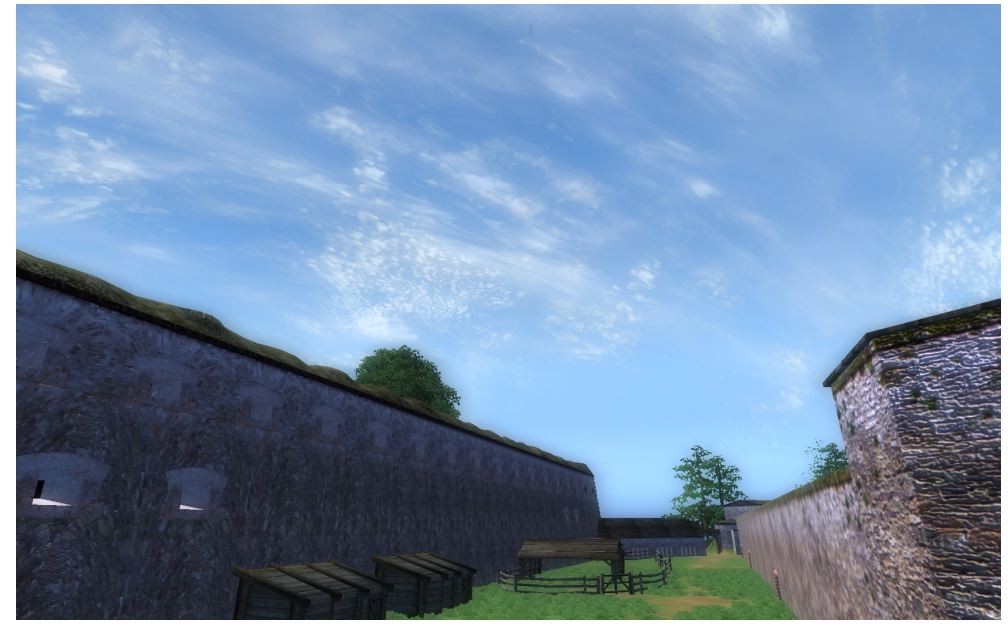

Fig. 5. The fortresses main wall (on the left) is connected to the common narrative element "crossing the threshold"

if the player chose the wrong uniform. Furthermore, the player has to perform authentic tasks coming up as the Prussians arm the fortress. Last, but not least he has to investigate and exploit authentic weaknesses within the fortification system in order to advance to the fortresses headquarters.

Game Technology. The Eduventure-II-prototype is a modification of the roleplaying-game "The Elder Scrolls IV: Oblivion" [22]. Oblivion seemed like a fair choice because of its freely available construction set (used for creating 
modifications) and its progressive technology (e.g. graphics rendering, facial animation of NPCs, support of heightmaps and so forth). Customised virtual models were built and textured using $3 \mathrm{ds}$ Max 23. The virtual fortress was created on the basis of real ground plans and satellite images (for the structure) and photographs (for the textures).

\subsection{Player Reactions}

Due to cut of funding, our findings on player reactions rest upon occasional, informal observations with only a handful of individuals instead of the originally intended, methodologically elaborated evaluation. Although this may have led to a lack of validity (considering statistical standards), our first experiences seem to confirm both assumptions regarding perception and reduced knowledge acquisition and increased motivation due to coherent game design (cf. section 4).

Regarding motivational effects, the game engines aesthetics seemed to attract young players. An early version of the Eduventure's prototype was presented at the computer expo "Cebit" in 2007 and seemed to be quite an eye-catcher. Young visitors enjoyed the aesthetics of the virtual fortress and characters. These players did not know about the educational purpose of the Eduventure. They just moved around the virtual territory and interacted with the game for the sheer fun of it. Unfortunately, it is an open question if they recognised any of the curricular contents of the game. However, they clearly had fun playing the game and were not "scared away" by stilted and artificial game design. Thus, the approach to educational game design as described above seems to preserve game structure and entertainment.

Older players provided some insights on the perception of the educational content. They had been told about the didactical intentions of the game. As a result, they expected a distinct presentation of educational content, pointed out by cues (cf. section 4.2), which they could not find due to the "subtle" design approach.

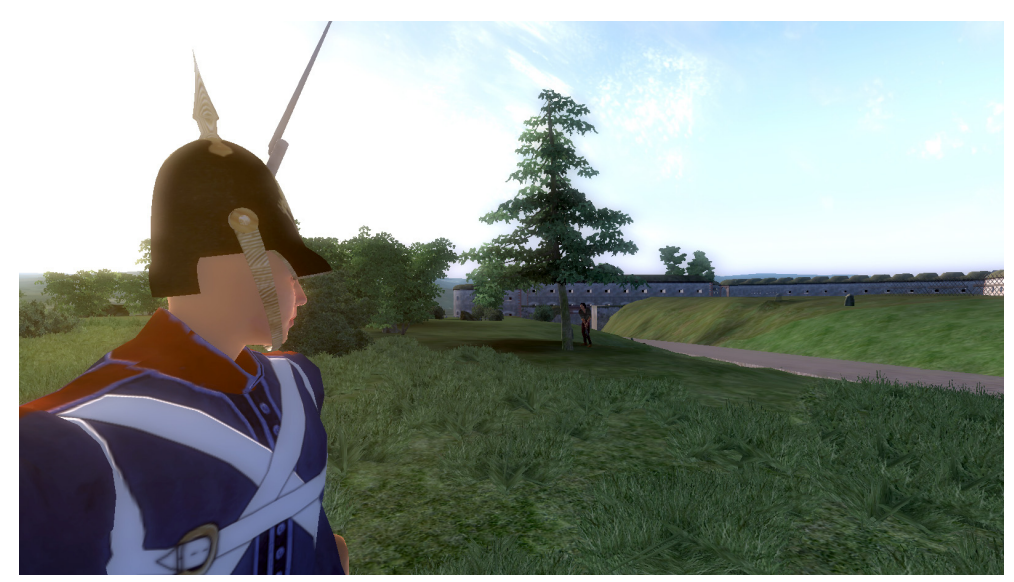

Fig. 6. A virtual Prussian Soldier in front of the fortress 
One player even played several parts of the prototype and finally asked: "Okay, but where is the educational content?" Concerning our goal to overcome the gap between educational content and gameplay in order to preserve entertainment and motivation, this could be considered as a positive result. Subtle educational game design prevents the game from becoming "teacherised", thereby supporting motivation and entertainment. However, when it comes to instructional potential, the informal game design and absence of "educational framing clues" (cf. section 4.2) may cause players to overlook educational content. It is still unclear if this leads to reduced knowledge acquisition.

\section{Lessons Learnt}

In conclusion, subtle educational game design, which connects curricular elements to gameplay, story and simulation, preserves game structure. This has a positive effect on the players' engagement and motivation. However, compared to conventional educational game design, this approach apparently leads to framing processes which make the players mentally remain within the magic circle (cf. section (2). As a consequence, one might suggest to add more curricular cues to the gameplay and its social context in order to conduct the players away from the magic circle back to reality. But this could possibly amplify the constitutional conflict of play vs. seriousness mentioned above (cf. section 3.2). This issue is currently treated by a new project of our working group (cf. section 7 ).

Within the scope of the Eduventure-II-project, we experienced that in practice theoretical thoughts may lose some of their discriminatory power. Lindley's framework of semiotic levels within video games is a great tool for analysing games. However, in practice, borders between semiotic layers may become blurred. For instance, within a role-playing game, gameplay and narrative usually interdepend: The plot produces game objectives, which, in return, affect the story. Therefore, the distinction between two layers of semiotic encoding is sometimes more of a theoretical nature, as the practical game experience seems to take place on several blended semiotic layers. This does not only affect game design, but also its evaluation (for instance when one tries to find out if it makes any difference if curricular information is connected to the gameplay layer instead to the narrative). Therefore, for evaluation purposes it is important to keep these layers apart from each other in practical gameplay. Otherwise, one would produce measurement artefacts, thereby reducing the significance of his research results.

Apart from that, there are other factors influencing the impact of educational games. Scientists point out that not only the content, but also the amount of video game play, as well as interaction mechanics, may significantly affect learning outcomes [24]. Furthermore, some curricular contents may receive more attention than others (especially when connected to different semiotic layers or even different game tasks). These effects may be hard to foresee in advance.

Investigating the instructional and motivational potential of a game design approach as described above requires a functional, well designed game with high discriminatory power. Complex games and game engines (like the 
Eduventure-II-prototype) may not be ideal for this purpose, for they can sustain exceptionally many technical pitfalls. Therefore, one might consider to concentrate on less complex game types like casual games, implemented within a less complex framework (e.g. Adobe Flash). Moreover we would encourage interdisciplinary projects, bundling resources and competencies of academics (from both educational and computer science) as well as professional game designers. This way, scientists could concentrate on their research and leave the practical design tasks to the experience and creativity of game designers.

\section{Future Work}

Framing processes and knowledge acquisition within computer games are highly complex, theoretical concepts, which have not yet been entirely investigated. For example, not only the game design and method of knowledge encoding may function as clues used during the framing process. The social and situational context in which the player encounters the game may play an important role as well. As a result, the issue of player perception within "subtle" educational games needs further research.

This also applies to the issue of motivational aspects. Connecting educational content to the semiotic structure of the video game might solve the problem of inferior and therefore unexciting educational game design. However, it is still unclear if the hypothetical constitutional conflict of play vs. seriousness (cf. section (3.2) has any impact on the players' engagement.

Both didactical and motivational issues are addressed by a research project currently carried out by the Institute For Computational Visualistics at the University of Koblenz-Landau, Germany. The objectives of this project are

- to develop and evaluate a theoretical framework specifying the impact of context and clues on cognitive framing

- and to measure potential effects of framing processes on both motivation and information.

Primarily, the computer games required for these tasks will be small and uncomplicated casual games based on Adobe Flash. In the meantime, our team is establishing contact to prospective game designers that might support us in designing the games.

\section{References}

1. Salen, K., Zimmerman, E.: Rules of Play. In: Game Design Fundamentals. MIT Press, Cambridge (2004)

2. Fabricatore, C.: Learning and videogames: An unexploited synergy. In: 2000 AECT National Convention, Long Beach (2000), http://www.learndev.org/dl/FabricatoreAECT2000.PDF (retrieved March 29, 2009)

3. Juul, J.: Half-real. In: Video Games between Real Rules and Fictional Worlds. The MIT Press, Cambridge (2005) 
4. Royle, K.: Game-Based Learning: A Different Perspective. Innovate 4(4) (2008), http://innovateonline. info/?view=article\&id=433 (retrieved March 29, 2009)

5. CAT2 Lab: Triple A Game Show (n.d.), http://scil.stanford.edu/news/game4-06.htm (retrieved March 29, 2009)

6. Gentile, D.A., Gentile, J.R.: Violent Video Games as Exemplary Teachers: A Conceptual Analysis. Journal of Youth and Adolescence 37(2), 127-141 (2008), http://www.springerlink.com/content/7706114365625653/ (retrieved March 29, 2009)

7. van Eck, R.: Digital Game-Based Learning. It's Not Just the Digital Natives Who Are Restless. Educause review, (March/April 2006), http://www.educause.edu/ir/library/pdf/erm0620.pdf (retrieved March 29, 2009)

8. Gee, J.G.: What video games have to teach us about learning and literacy. Palgrave Macmillan, New York (2003)

9. Procedural Arts: Facade (2005), http://www.interactivestory.net (retrieved March 29, 2009)

10. Mitchell, A., Savill-Smith, C.: The use of computer and video games for learning. A review of the literature. Learning and Skills Development Agency (2004), http://www.lsda.org.uk/files/PDF/1529.pdf (retrieved March 29, 2009)

11. Becta: Computer Games in Education project: Aspects (2001), http://snipurl.com/becta2001 (retrieved March 29, 2009)

12. Prensky, M.: Digital game-based learning. McGraw-Hill, New York (2001)

13. Squire, K.: Changing the Game: What Happens When Video Games Enter the Classroom? Innovate, 1(6) (2005), http://innovateonline.info/index.php?view=article\&id=82 (retrieved March 29, 2009)

14. Papert, S.: Does easy do it? Children, Games and Learning. Game developer magazine (June 1998), http://www.papert.org/articles/Doeseasydoit.html (retrieved March 29, 2009)

15. Lindley, C.A.: The Semiotics of Time Structure in Ludic Space As a Foundation for Analysis and Design. Game Studies 5(1) (October 2005), http://www.gamestudies.org/0501/lindley/ (retrieved March 29, 2009)

16. Atari: Pong (1972)

17. Adams, E., Rollings, A.: Fundamentals of Game Design. Prentice Hall, Upper Saddle River (2006)

18. Glassner, A.: Interactive Storytelling. Techniques for 21st Century Fiction. A K Peter, Natick (2004)

19. Firaxis: Civilization IV (2005), http://www.civilization.com (retrieved March 29, 2009)

20. Anderson, J.: Cognitive Psychology and its Implications. Worth Publishers, New York (2005)

21. Robinson, T.N., Borzekowski, D.L.G., Matheson, D.M., Kraemer, H.C.: Effects of Fast Food Branding on Young Childrens Taste Preferences. Archives of Pediatrics and Adolescent Medicine 161(8), 792-797 (2007)

22. Bethesda Softworks: The Elder Scrolls IV: Oblivion (2006), http://www.elderscrolls.com/games/oblivion_overview.htm (retrieved March 29, 2009)

23. Autodesk: 3ds Max (n.d.), http://www.autodesk.com/3dsmax (retrieved March 29, 2009)

24. Rosser, J.C., Lynch, P.J., Haskamp, L., Gentile, D.A., Yalif, A.: The impact of video games in surgical training. Archives of surgery 142(2), 181-186 (2007), http://archsurg.ama-assn.org/cgi/reprint/142/2/181 (retrieved March 29, 2009) 